that the recently discovered retrograde satellites complicate the centrifugal hypothesis is no serious argument against this hypothesis. They can be made to fit into a general modified scheme. With regard to the earth-moon system, the criticism based upon the irregularity of present-day ocean tides seems irrelevant to the main issue. In the past, at any rate, we must look to regular body tides in the earth as the main factor in tidal evolution; of these tides, as mathematical analysis shows us, a natural result is a retardation of rotation. There are several further criticisms of interest in the paper, notably the reminder that the moon, if brought down to the surface of the earth (assumed to be of its present size), would be inside the limit given by Roche's criterion of stability, and would split into fragments. This point has already been considered by Sir G. Darwin (Nature, 1886). In his discussion of it he abandons any idea that his theory explains the actual method of genesis of the moon, while he claims that it is of importance in dealing with the moon's later history.

The dynamical arguments of the paper are reinforced by geological arguments. It is shown that there is no geological evidence supporting the view that in earlier times the earth's rotation was much more rapid, and consequently the earth itself much more oblate than at present. The greater part of the changes must have taken place before the earth had solidified and its surface had become a book for the geologist to read. Only on such terms will the geologist accept the tidal theory, and on this particular point he has the support of Kelvin. In view of recent discoveries of unsuspected sources of heat and energy, it seems that the necessary extension of time involved in this requirement of the geologist may be granted by the physicist, and that the theory need not be abandoned by the mathematician at the bidding of the geologist.

Prof. Moulton's line of attack is quite distinct from that of his colleague. By considerations of energy and momenta alone he traces back the earth-moon system under various simplifying assumptions to the time when day and month were equal. He obtains in all cases a distance between the centres of the two bodies of more than 9000 miles. This result is very much the same as that originally found by Sir G. Darwin, but the latter suggested, without examining the point very closely, that a consideration of the sun's tidal effect would greatly diminish this distance. Prof. Moulton proves that the actual difference due to this cause is very slight, and his conclusion strongly reinforces the view that fission must have taken place, if at all, at a time when the earth was much less dense than at present. The further contention that the fission could not have been the result of increased rotation alone has already been recognised as valid by Sir G. Darwin. The latter's suggestion that the coincidence of a solar tide with a free period of oscillation of the earth might have led to a condition of instability has been examined by Prof. Love (Phil. Mag., March, I889), who showed the idea to be quite feasible.

Of the remaining papers in the volume, which deal mainly with special points discussed by Chamberlin or Moulton in relation to the wider problem, the most interesting is an examination by Dr. Lunn of the heat which would be developed in the building up of a planet according to the planetesimal theory. A general qualitative agreement with the known requirements of facts is reached. More could, perhaps, hardly be looked for. Perhaps the following general criticism of the planetesimal theory may be made at its present stage of development. In many respects it gives a general qualitative agreement with observed facts, NO. 2073, VOL. 8I] while its supporters are criticising older theories on the ground that they lack at times a close quantitative agreement with observed facts. It remains to be seen whether the newer theory will come up to the standard by which the older theories are being judged.

\section{F. Stratton.}

\section{PROF. SIMON NEWCOMB.}

$\mathrm{BY}$ the death of Prof. Simon Newcomb science has sustained one of the most severe blows of recent years. America has lost her most eminent man of science, and not since the death of Adams has the world been deprived of so illustrious an investigator in theoretical astronomy. Newcomb's career up to I899 was described by Loewy in the article on "Scientific Worthies" in Nature, vol. 1x., p. I, and his activity and marvellous powers of work continued up to the date of the illness that has just terminated fatally. Since 1899 he has given us his interesting book entitled "The Reminiscences of an Astronomer" (1903), in which he described the early incidents of his life and related the extraordinary circumstances by which his steps were guided into the career which led him to such eminence.

Newcomb commenced his reminiscences with the words :- "I date my birth into the world of sweetness and light on one frosty morning in January, 1857 , when I took my seat between two well-known mathematicians (Winlock and Runkle) before a blazing fire in the office of the "Nautical Almanac' at Cambridge, Mass."

Though born at Wallace, in Nova Scotia, March I2, I835, Simon Newcomb was of almost pure New England descent. His father was, he tells us, the most rational and the most dispassionate of men, who, when he had reached the age of twenty-five, set forth to search for a wife who possessed the qualities most suitable in a helpmeet. His search had extended nearly a hundred miles before, in the village of Moncton, he found in Emily Prince what he desired, and his son says the marriage was "in all respects a happy one, so far as congeniality of nature and mutual regard could go."... "My mother was the most profoundly and sincerely religious woman with whom I was ever intimately acquainted, and my father always entertained and expressed the highest admiration for her mental gifts, to which he attributed whatever talents his children might have possessed. The unfitness of her environment to her constitution is the saddest memory of my childhood. More I do not trust myself to say to the public, nor will the reader expect more of me."

How Newcomb's early years were passed may perhaps be conjectured from the fact that the autobiographical chapter in which he records them bears the title of "The World ot Cold and Darkness." He had, however, from his earliest years a keen desire for knowledge, and read whatever books were available. His first introduction to the intellectual career he desired was not promising. In those days there was a so-called physician, Dr. Foshay, living near Moncton, who was reputed to have effected cures of sick persons given up by other doctors. As Newcomb says, "Diomeds of the medical profession before whose shafts all forms of disease had to fall were then very generally supposed to be realities." By the intervention of an aunt, young Newcomb agreed to live with the doctor, rendering him all assistance in preparing medicines, while the doctor, on his part, undertook to supply Newcomb's bodily needs and teach him " the botanic system of medicine." After a little experience it began to dawn upon Newcomb that Dr. Foshay, notwithstanding his 
boasted medical skill, was no more than an ignorant pretender, and that the time of his assistant would be utterly wasted instead of being, as he expected, expended on studying botany and scientific medicine. So on September 13, I853, Newcomb determined to run away after leaving a letter for the doctor, in which he explained that, as the doctor had shown no indication of fulfilling his promises, his assistant felt that the arrangement was annulled. Newcomb was on the road before daybreak, and walked until late at night, ever fearing pursuit from the doctor. It appears that the doctor did actually attempt a pursuit, but, by good fortune, Newcomb eluded recapture, and at last reached a house where he was hospitably entertained. "Thus ended," he says, " a day which I have always looked back to as the most memorable in my life."

After a week of hardship, which Newcomb says he will not harrow the feelings of the reader by describing, he arrived at Calais, where he found a boat bound for Salem. The little money that he had in his pocket was less than the price of the passage, but he undertook to supplement the deficiency by working his way. A few months later we find him engaged as a teacher in a school at a place called Massey's Cross Roads, in Kent County, and devoting every spare hour to reading whatever mathematical books he could obtain. His first appearance as an author was in refutation of a Mr. Eveleth, who doubted the Copernican system, and Newcomb published in the National Intelligencer an exposition of the fallacies in the paradoxer's essay. In 1856 he was teaching in the family of a planter, near Washington, and on a visit to the library of the Smithsonian Institution he was delighted to see among the mathematical books the greatest treasure that his imagination had ever pictured, a work that he had thought of almost as belonging to fairyland-Laplace's "Mécanique Céleste." Shortly afterwards he summoned up enough courage to seek for an interview with Prof. Henry, who suggested that he should look for some position in the Coast Survey, and his reception by Mr. Hilgard was such that Newcomb writes:- "I found from my first interview with him that the denizens of the world of light were up to the most sanguine conceptions I ever could have formed." Mr. Hilgard introduced him to Prof. Winlock, of Cambridge, Mass., and thus in 1857 he entered " the world of sweetness and light" by becoming one of the computers in "The American Ephemeris and Nautical Almanac."

From this time the progress of Newcomb to the height of astronomical fame was unchecked. Dr. Gould, the well-known astronomer, wrote to tell him that there was a vacancy in the Corps of Professors of Mathematics attached to the Naval Observatory at Washington, and suggested that he might like the post. Newcomb at first was disinclined to consider the proposition. Cambridge seemed to him the focus of the science and learning of his country. He also rather shrank from what he called the drudgery of night work in the observatory, for he considered that it would interfere with the mathematical investigations in which he was specially interested; but he finally decided to apply, and a month later, September, $\mathrm{I} 86 \mathrm{r}$, was much gratified in receiving the appointment duly signed by Abraham Lincoln. Newcomb accordingly settled in Washington, where he married, in I863, Mary Caroline, daughter of Dr. C. A. Hassler, U.S. Navy, and three daughters were the issue of the marriage.

In the winter of I87o Mr. Cyrus Field, of Atlantic cable fame, had a small dinner-party at the Arlington Hotel, Washington. A young son of Mr. Field's was present, who had spent the day in seeing the sights NO. 2073, vOL. $8 \mathrm{I}]$ of Washington. The youth described his visit to the observatory, and expressed his surprise in not finding any large telescope. The guests were at first incredulous, but, finding that the statement was true, a senator who was present declared that this must be rectified, and in due course Alvan Clark and Sons were entrusted with the manufacture of a great objective of 26-inches aperture.

Newcomb was specially interested in this enterprise, because, as he says, "the work of reconstructing the tables of the planets, which I had long before mapped out as the greatest one in which I should engage, required as exact a knowledge as could be obtained of the masses of all the planets. In the case of Uranus and Neptune, the two other planets, this knowledge could best be obtained by observations on their satellites. To the latter my attention was therefore directed." In 1875 the instrument was given over to Prof. Asaph Hall, and of course it has become for ever famous as the means by which Hall made his beautiful discovery of the two satellites of Mars.

In Newcomb's "Reminiscences" we find, in a chapter on "The Author's Scientific Work," a most interesting sketch of the great problems to the solution of which his life's work was devoted. It appears that the first important investigation on which he entered in his early years at Cambridge, Mass., related to the orbits of the asteroids. This particular investigation discussed the theory that these bodies originated as fragments of a large planet broken up by some cataclysm. It involved an extended examination of the secular perturbations of the orbits of the asteroids to determine whether at any epoch even hundreds of thousands of years ago all the orbits passed through one point, though by the influence of perturbations they have now ceased to do so. The investigation seems to show that no such cataclysm as that looked for ever occurred, and that each of the asteroids has been a separate body since the solar system came into existence.

Another problem which shows the lines of thought habitually present to Newcomb may be thus stated. Do the mutual attractions of the sun, planets, and satellites completely explain all the motions in the solar system? or, as he expressed it, "Does any world move otherwise than as it is attracted by other worlds?" This opens up two great researches : first, in bringing the labours of astronomers together so as to determine with the utmost accuracy the actual movements of the heavenly bodies, and, second, in securing all attainable perfection in the mathematical methods employed in their examination. A very important branch of this inquiry is presented by the movements of the moon. Such an investigation as Newcomb sketched out had a stimulating effect on the discussion of old and valuable observations of the positions of the moon deduced from ancient eclipses, and much of Newcomb's best work was done in connection with the lunar theory.

In 1875 Newcomb was offered the position in Harvard University which is now filled with such distinction by Prof. Pickering, but he declined this offer after careful consideration. On September $1_{5}, 1877$, he was appointed editor of "The American Ephemeris and Nautical Almanac." $\mathrm{He}$ tells us that "the change was one of the happiest of my life. I was now in a position of recognised responsibility where my recommendations met with the respect due to that responsibility, where I could make plans with the assurance of being able to carry them out." $\mathrm{He}$ approached the duties of this office in the loftiest spirit, and devoted his energies to the task of improving the fundamental constants employed. With this object in view, extensive investigations in 
various parts of dynamical astronomy had to be undertaken. His efforts were unremitting to improve at every point the processes of calculation, as well as the materials on which the calculations were based. Among the greatest of Newcomb's labours, measured by their value to science, are, undoubtedly, those done in connection with this office. Astronomers all over the world recognise "The Astronomical Papers of the American Ephemeris" brought out under Newcomb's guidance as works of classical value. In this great task he had the good fortune to obtain the assistance of many eminent men, among whom was Mr. George W. Hill, who, in Newcomb's generous words, "will easily rank as the greatest master of mathematical astronomy during the last quarter of the nineteenth century." Newcomb's important "Compendium of Spherical Astronomy," published in I906, should also be mentioned in connection with the "Astronomical Papers." After his term of service in the office of the American Ephemeris had expired in $I 883$ by the age-limit. Newcomb became professor of mathematics and astronomy in Johns Hopkins University in Baltimore, and this post he held until I893.

As in the case of other men who have risen to a foremost position in science, Newcomb was wonderfully versatile. He was, as we have seen, a leader among mathematical astronomers, he did good work on various occasions in practical observation, and that he was a skilful experimenter when occasion required is shown by his beautiful investigations of the velocity of light; but Newcomb also wrote a number of books intended more for the general public than for technical astronomers. His "Popular Astronomy " is universally recognised as an admirable work full of lofty thought and luminous suggestion. It is remarkable for its literary grace no less than for its scientific accuracy, and those who had the privilege of enjoying Prof. Newcomb's friendship will recognise throughout "Popular Astronomy" indications of that quaint humour which was so characteristic of the author. He wrote many other books; he was recognised as an authority on economics and life assurance, and he even wrote a novel, though I do not know whether this particular venture was sufficiently successful to encourage a repetition of the experiment. All the honours which his own country or other countries could bestow on a man of science were liberally showered on him with universal approval.

It need hardly be said that for a self-taught man to become one of the most consummate mathematicians of his day, and one of the great leaders of science, not only great abilities, but indomitable industry were necessary. Newcomb was an indefatigable worker. From morning until night he was at his desk, and yet such was the kindliness of the man that when a demand on his time and friendship was made by a brother astronomer or mathematician, his books were laid aside, and he would devote himself assiduously to a day of gracious offices for his visitor. Newcomb had a serious illness about fifteen years ago, but he made a remarkable recovery, and until the last few months he was still hard at work. $\mathrm{He}$ died after a long illness on July II, Igog.

Thus passes from the world the most conspicuous figure among the brilliant band of contemporary American astronomers. His inspiring example will long be treasured by those who were acquainted with his work. His habitual loftiness of thought, nobility of character, dignified courtesy, and ever-ready helpfulness endeared him to his many friends on both sides of the Atlantic. His private acts of quiet kindness and goodness of heart will be affectionately cherished by those fortunate persons to whom they are known.

NO. 2073 , VOL. 81 ]

\section{NOTES.}

The first attempt to cross the Channel by aëroplane was made by M. Latham on Monday, July 19. The machine, which is a monoplane, started from Sangatte, and was about 600 feet above sea-level when it left the land. This altitude was increased to about rooo feet, and a speed of between forty and forty-five miles an hour was attained. After travelling about eight miles from the shore in the direction toward Dover the engine stopped, and the monoplane glided steadily down in a straight line to the water, where it floated until the destroyer Harpon came up about five minutes later. M. Latham was then taken on board, and his monoplane towed into Calais harbour.

THE death is announced of M. Henri de Parville, who was for several years editor of La Nature, and more recently a contributor to Cosmos. M. de Parville did much useful work in the direction of instructing and interesting the French public in the achievements of science. Primarily an engineer, he was well versed in other branches of pure and applied science, and for many years devoted the greater part of his energies to work for the scientific Press.

The Institute of Metals has just completed the first year of its existence, during which period the membership has increased from barely two hundred to well over five hundred. The autumn meeting of the association will he held at Manchester on Thursday and Friday, October I4 and 15. A series of about half a dozen papers will be read and discussed at the two morning sessions of the institute. The afternown of the first day will be devoted to a visit to the University of Manchester, where members will be received officially, on behalf of the University, by Vice-Chancellor Alfred Hopkinson, K.C. The new engineering laboratories will be open for inspection, and facilities will also be given for inspecting the Municipal School of Technology. In the evening a reception will be held by the Lord Mayor at the Town Hall. During the afternoon of Friday, October 15, members will have the opportunity of visiting works of metallurgical interest in the neighbourhood of Manchester.

The committee nominated by the Paris Academy of Sciences for the distribution of the Bonaparte fund $(25,000$ francs) for 1909 has received thirty-five applications, only nine of which are considered to conform with the regulations laid down by the committee of 1908 . It is proposed to allocate the fund as follows: -4000 francs to M. Cayeux, to enable him to pursue his researches on the fossils of the Oolitic iron deposits in the United States; 4000 francs to $M$. Chevalier, to assist him in carrying on his geographical and ethnographical researches in the French colonies in tropical Africa; 4000 francs to $M$. Pérez, to assist in the publication of his memoir entitled "Recherches histologiques sur les Métamorphoses des Muscides"; 3000 francs to M. Houard, to enable him to proceed to Corsica, Algeria, and Tunis to collect material for his anatomical and physiological studies; 2000 francs to M. Berget, for the construction of an apparatus for the study of the distribution and intensity of gravity; 2000 francs to $M$. Bernard, to continue his studies of the variation of the solar radiation and the illumination of the sky in the immediate neighbourhood of the sun; 2000 francs to $M$. Blaringhem, for the continuation of his experimental researches on the variation of species; 2000 francs to $M$. Estanave, for the continuation of his researches on stereoscopic projection by direct vision, stereoradiography, and autostereoscopy ; 2000 francs to M. Mathias, to enable him to continue in the cryogenic laboratory of Leyden his re. 